\title{
Synthesis and Characterization of New Aromatic Polyamides Bearing Crown Ethers and Acyclic Ethylene Oxide Units in the Pendant Structure. III. Benzo-18-crown-6 Systems and Their Open-Chain Counterparts
}

\author{
VERÓNICA CALDERÓN, ${ }^{1}$ GERT SCHWARZ, ${ }^{2}$ FÉLIX GARCÍA, ${ }^{3}$ MARÍA J. TAPIA, ${ }^{3}$ ARTUR J. M. VALENTE, \\ HUGH D. BURROWS, ${ }^{4}$ JOSÉ MIGUEL GARCÍA ${ }^{3}$ \\ ${ }^{1}$ Departamento de Construcciones Arquitectónicas e Ingenierías de la Construcción y del Terreno, \\ Escuela Politécnica Superior, Universidad de Burgos, Villadiego s/n, E-09001 Burgos, Spain \\ ${ }^{2}$ Institut für Technische und Makromolekulare Chemie, Universität Hamburg, Bundesstrasse 45, \\ D-20146 Hamburg, Germany \\ ${ }^{3}$ Departamento de Química, Facultad de Ciencias, Universidad de Burgos, Plaza de Misael Bañuelos s/n, \\ E-09001 Burgos, Spain \\ ${ }^{4}$ Departamento de Química, Universidade de Coimbra, 3004-535 Coimbra, Portugal
}

Received 4 May 2006; accepted 31 July 2006

DOI: 10.1002 / pola.21710

Published online in Wiley InterScience (www.interscience.wiley.com).

\begin{abstract}
We report the synthesis and characterization of 10 novel polyamides containing the benzo-18-crown-6 subunit and its dipodal counterpart, along with their properties, and a comparison with homologous polyamides bearing benzo-12-crown-4, benzo-15-crown-5, and the corresponding dipodal systems. The anomalous polymerization of some of the diacid monomers, that leads to insoluble gels under standard Yamazaki polymerization conditions, is described. The gel formation has been attributed to the threading of cyclic oligoamides with a growing polyamide chain to yield rotaxanes, polyrotaxanes, catenanes, or polycatenanes. Polyamide macrocycles have been characterized with matrix-assisted laser desorption/ionization time-of-flight mass spectrometry. A route to avoid gel formation, consisting of a lower initial monomer concentration, is also described, along with the polymer properties of the polyamides obtained, including the chemical characterization, mechanical behavior, water sorption, morphology, diffusion data, and permeability of membranes prepared with these polymers. () 2006 Wiley Periodicals, Inc. J Polym Sci Part A: Polym Chem 44: 6252-6269, 2006

Keywords: catenanes; cycles; gelation; mechanical properties; membranes; monomers; polyamides; rotaxanes; thermal properties; WAXS
\end{abstract}

Correspondence to: J. M. García (E-mail: jmiguel@ubu.es) Journal of Polymer Science: Part A: Polymer Chemistry, Vol. 44, 6252-6269 (2006) () 2006 Wiley Periodicals, Inc.

\section{INTRODUCTION}

Mankind has ever tried to mimic Nature for commercial or scientific purposes, and hostguest chemistry is only one example of this phenomenon. The ability of biological molecules, 
such as porphyrins and valinomycin, to selectively bind cations has particularly attracted the attention of researchers.

From a chemical point of view, the lone pairs of the ether groups of chemical products can interact intermolecularly or intramolecularly with electrondeficient atoms or chemical groups, resulting in the overall stabilization of the system. The interaction of the ether groups with cations through ion-dipole interactions is particularly favored when various ether groups are regularly located in an aliphatic cycle structure in the so-called crown ethers. Thus, the crown ethers or coronands are cyclic polyoxapolymethylene structures, in which the constitution of the commonest crown ethers is the oligooxyethylene sequences. The ability of these structures to selectively interact with cations through ion-dipole interactions has attracted the attention of researchers since its discovery by Charles J. Pedersen. ${ }^{1,2}$ The open-chain counterparts of the crown ethers are called podands, or podal structures, and are acyclic host molecular structures with binding sites for guest molecules. ${ }^{3}$

The present and future technological applications of crown ethers and podands include the sensing and manufacture of ion-selective electrodes; the development of liquid membranes or supported liquid membranes employing the selective transport capabilities of these molecules; the production of selective extraction systems of chemicals for purification, recovery, or decontamination; and the production of catalysts for organic and inorganic reactions.

However, discrete crown or podand compounds lack chemical stability, need physical support for most applications, migrate and can be extracted from this support, and are soluble in most organic and inorganic solvents; this complicates their separation and recovery. However, the preparation of polymers with crown or podand moieties chemically anchored to a polymer backbone solves these problems.

On the basis of these considerations, it would seem that high-performance aromatic polyamide backbones, along with pendant dipodal or crown moieties, are excellent candidates for advanced technological application under extreme conditions, such as cation sensing and waste recovery of cations through a reversible and reusable solidliquid extraction technology, for cation membrane transport applications for purification or recovery, and for synthetic purposes.

In previous articles, ${ }^{4,5}$ we reported the synthesis and characterization of new aromatic polyamides bearing benzo-12-crown-4, benzo-15-crown-15, and their dipodal counterparts as pendant substructures. In this work, we extend that study to polyamides containing pendant moieties of benzo-18crown- 6 and their dipodal counterparts.

This work describes the tendency of the higher ring-membered crown ether and podand monomers to give insoluble gels during polymerization because of the high propensity to yield cyclic systems and thus to give a network though cycle threading to finally produce rotaxanes, polyrotaxanes, catenanes, and polycatenanes.

This gel formation has been overcome by the modification of the polymerization conditions. Thus, soluble polyamides with pendant crown of podand moieties have been obtained, and the thermal, mechanical, and transport properties, along with the water sorption, have been studied and correlated with the chemical structure of the structural unit, with a focus on the pendant crown ether subunits and their dipodal counterpart moieties.

In addition, the thermal or mechanical properties, together with the water uptake, have been studied and correlated with the chemical structure for polyamides with pendant benzo-12-crown-4, benzo-15-crown-5, benzo-18-crown-6, and their dipodal counterparts. Moreover, we have analyzed the morphology and permeability of membranes prepared with these polymers and also report water sorption and diffusion data.

\section{EXPERIMENTAL}

\section{Materials}

All materials and solvents were commercially available and were used as received, unless otherwise indicated. $N$-Methyl-2-pyrrolidone (NMP) was vacuum-distilled twice over phosphorous pentoxide and then stored over $4-\AA$ molecular sieves. Lithium chloride was dried at $400{ }^{\circ} \mathrm{C}$ for $12 \mathrm{~h}$ before use. Triphenylphosphite (TPP) was vacuum-distilled twice over calcium hydride and then stored over 4 - $\AA$ molecular sieves. Pyridine was dried under reflux over sodium hydroxide for $24 \mathrm{~h}$ and distilled over $4-\AA$ molecular sieves. $m$-Phenylenediamine (MPD), $p$ phenylenediamine (PPD), 4,4'-diaminediphenyl sulfone (DDS), and 4,4'-diaminediphenyl ether (DDE) were commercially available and were purified by double-vacuum sublimation. 2,2-Bis(4-aminobenzo)-1,1,1,3,3,3-hexafluoropropane (6F) was crystallized from ethanol. The synthesis of 1,14dichloro-3,6,9,12-tetraoxatetradecane, 1-chloro-3,6, 
9-trioxaundecane, and ethyl 3,4-dihydroxybenzoate was accomplished according to the procedures previously described. ${ }^{6}$

\section{Intermediates and Monomers}

\section{4-Ethoxycarbonyl-benzo-18-crown-6}

A 1-L flask fitted with a condenser and a mechanical stirrer was charged with $500 \mathrm{~mL}$ of dimethylformamide (DMF) and potassium carbonate (33.4 $\mathrm{g}, 240 \mathrm{mmol})$. Upon stirring and heating to $150{ }^{\circ} \mathrm{C}$, a mixture of ethyl 3,4-dihydroxybenzoate $(20.0 \mathrm{~g}$, $110 \mathrm{mmol}$ ) and 1,14-dichloro-3,6,9,12-tetraoxatetradecane (30.2 g, $110 \mathrm{mmol}$ ) was dropped slowly into the reaction flask. After that, the system was maintained at $150{ }^{\circ} \mathrm{C}$ for $24 \mathrm{~h}$. The solvent was then removed, and the crude product that was obtained was extracted with dichloromethane. The organic phase was washed twice with alkaline water, vacuum-concentrated to dryness, and finally extracted with boiling hexane. Upon the cooling of the hexane solution, white crystals of 4-ethoxycarbonyl-benzo-18-crown- 6 were obtained. The extraction procedure with hexane was repeated until no more crystals were obtained upon the cooling of the organic phase.

Yield: 19.0 g (45\%). mp: $69 \pm 1{ }^{\circ} \mathrm{C} .{ }^{1} \mathrm{H}$ NMR [deuterated chloroform $\left(\mathrm{CDCl}_{3}\right), \delta, \mathrm{ppm}$ ]: 7.61 $(\mathrm{dd}, 1 \mathrm{H}) ; 7.51(\mathrm{~d}, 1 \mathrm{H}) ; 6.82(\mathrm{~d}, 1 \mathrm{H}) ; 4.28(\mathrm{q}, 2 \mathrm{H})$; $4.16(\mathrm{~m}, 4 \mathrm{H}) ; 3.90(\mathrm{~m}, 4 \mathrm{H}) ; 3.73(\mathrm{~m}, 4 \mathrm{H}) ; 3.68$ $(\mathrm{m}, 4 \mathrm{H}) ; 3.64(\mathrm{~s}, 4 \mathrm{H}) ; 1.33(\mathrm{t}, 3 \mathrm{H}) .{ }^{13} \mathrm{C} \mathrm{NMR}$ $\left(\mathrm{CDCl}_{3}, \delta, \mathrm{ppm}\right): 166.34 ; 152.90 ; 148.26 ; 123.80$; $122.98 ; 114.47 ; 112.11 ; 70.95 ; 70.80 ; 70.69$; $69.48 ; 69.37 ; 68.93 ; 68.87 ; 60.59 ; 14.26$. Electron-impact low-resolution mass spectrometry (EI-LRMS) m/z: 384 (M+; 42); 209 (13); 208 (99); 193 (24); 180 (39); 165 (16); 163 (100); 73 (17).

\section{Ethyl 3,4-Bis-(2-(2-(2-ethoxyethoxy)ethoxy) ethoxy)benzoate}

This compound was prepared in a manner similar to that for 4-ethoxycarbonyl-benzo-18-crown6 from ethyl 3,4-dihydroxybenzoate $(20.0 \mathrm{~g}, 110$ mmol), 1-chloro-3,6,9-trioxaundecane $(43.2 \mathrm{~g}$, $220 \mathrm{mmol}$ ), potassium carbonate $(37.9 \mathrm{~g}, 275$ $\mathrm{mmol}$ ), and DMF (250 $\mathrm{mL}$ ). However, the crude product was not extracted with hexane but was employed directly in the next synthetic step without further purification.

Yield: $52.5 \mathrm{~g}(95 \%) .{ }^{1} \mathrm{H} \mathrm{NMR}\left(\mathrm{CDCl}_{3}, \mathrm{ppm}, \delta\right)$ : $7.63(\mathrm{dd}, 1 \mathrm{H}) ; 7.54(\mathrm{~d}, 1 \mathrm{H}) ; 6.88(\mathrm{~d}, 1 \mathrm{H}) ; 4.31(\mathrm{q}$, $2 \mathrm{H}) ; 4.19(\mathrm{~m}, 4 \mathrm{H}) ; 3.86(\mathrm{~m}, 4 \mathrm{H}) ; 3.72(\mathrm{~m}, 4 \mathrm{H})$; $3.63(\mathrm{~m}, 8 \mathrm{H}) ; 3.56(\mathrm{~m}, 4 \mathrm{H}) ; 3.49(\mathrm{q}, 4 \mathrm{H}) ; 1.35(\mathrm{t}$, $2 \mathrm{H}) ; 1.17(\mathrm{t}, 6 \mathrm{H}) .{ }^{13} \mathrm{C} \mathrm{NMR}\left(\mathrm{CDCl}_{3}, \mathrm{ppm}, \delta\right)$ : $166.36 ; 152.87 ; 148.11 ; 123.95 ; 123.36 ; 114.98$; $112.68 ; 70.99 ; 70.94 ; 70.74 ; 69.87 ; 69.67 ; 69.57$; $68.85 ; 68.60 ; 66.68 ; 60.83 ; 15.23 ; 14.46$. EILRMS m/z: 502 (M+; 19); 208 (18); 163 (11); 161 (26); 117 (48); 73 (100).

\section{4-Carboxybenzo-18-crown-6}

A 1-L, round-bottom flask fitted with a condenser was charged with 4-ethoxycarbonyl-benzo-18crown-6 (28.8 g, $75 \mathrm{mmol})$, ethanol (150 mL), and a solution of sodium hydroxide in water $(150 \mathrm{~mL}$, $25 \%$ ). The mixture was then refluxed for $6 \mathrm{~h}$, after which the solvent was removed in vacuo. The crude product was dissolved in $100 \mathrm{~mL}$ of water, and the mixture was acidified to $\mathrm{pH} 3$ with hydrochloric acid $(\mathrm{HCl})$ and extracted with dichloromethane. The organic phase was concentrated on a rotary evaporator, and a white solid appeared. The product was collected and dried overnight.

Yield: 23.0 g (86\%). mp: $111 \pm 1{ }^{\circ} \mathrm{C} .{ }^{1} \mathrm{H}$ NMR [deuterated dimethyl sulfoxide (DMSO- $\left.d_{6}\right)$, ppm, $\delta$ ]: $7.62(\mathrm{dd}, 1 \mathrm{H}) ; 7.48(\mathrm{~d}, 1 \mathrm{H}) ; 6.79(\mathrm{~d}, 1 \mathrm{H}) ; 4.13(\mathrm{~m}$, $4 \mathrm{H}) ; 3.87(\mathrm{~m}, 4 \mathrm{H}) ; 3.71(\mathrm{~m}, 4 \mathrm{H}) ; 3.65(\mathrm{~m}, 4 \mathrm{H}) ; 3.63$ $(\mathrm{s}, 4 \mathrm{H}),{ }^{13} \mathrm{C}$ NMR (DMSO- $d_{6}, \mathrm{ppm}, \delta$ ): 170.29; $152.68 ; 147.49 ; 123.90 ; 121.36 ; 113.74 ; 111.19$; $70.01-69.86(\mathrm{~m}) ; 68.68 ; 68.56 ; 68.21 ; 68.05$. EILRMS m/z: 356 (M+; 23); 224 (20); 180 (25); 165 (85); 137 (90); 124 (32); 79 (100).

\section{3,4-Bis-(2-(2-(2-ethoxyethoxy)ethoxy)ethoxy) benzoic Acid}

This compound was prepared in a manner similar to that for 4-carboxybenzo-18-crown-6 from 3,4-bis-(2-(2-(2-ethoxyethoxy)ethoxy)ethoxy)benzoic acid ethyl ester (50.2 g, $100 \mathrm{mmol})$, ethanol $(150 \mathrm{~mL})$, and a solution of sodium hydroxide in water $(150 \mathrm{~mL}, 25 \%)$.

Yield: $40.3 \mathrm{~g}(85 \%) .{ }^{1} \mathrm{H}$ NMR (DMSO- $d_{6}$, ppm, $\delta): 7.63(\mathrm{dd}, 1 \mathrm{H}) ; 7.54(\mathrm{~d}, 1 \mathrm{H}) ; 6.86(\mathrm{~d}, 1 \mathrm{H}) ; 4.17$ $(\mathrm{m}, 4 \mathrm{H}) ; 3.85(\mathrm{~m}, 4 \mathrm{H}) ; 3.71(\mathrm{~m}, 4 \mathrm{H}) ; 3.62(\mathrm{~m}$, $8 \mathrm{H}) ; 3.55(\mathrm{~m}, 4 \mathrm{H}) ; 3.48(\mathrm{q}, 4 \mathrm{H}) ; 1.16(\mathrm{t}, 6 \mathrm{H}) .{ }^{13} \mathrm{C}$ NMR (DMSO- $d_{6}, \quad$ ppm, $\delta$ ): 170.17; 153.09; $148.05 ; 124.59 ; 122.57 ; 114.87 ; 112.33 ; 70.82$; $70.78 ; 70.58 ; 69.73 ; 69.55 ; 69.40 ; 68.61 ; 68.39$; 66.64; 15.09. EI-LRMS $\mathrm{m} / z: 474(\mathrm{M}+; 18) ; 180$ (34); 161 (31); 117 (55); 73 (100); 59 (19).

\section{4-Chlorocarbonylbenzo-18-crown-6}

4-Carboxybenzo-18-crown-6 (17.8 g, $50 \mathrm{mmol})$ was refluxed with $14.6 \mathrm{~mL}$ ( $200 \mathrm{mmol})$ of thionyl 
chloride and three drops of DMF. After $4 \mathrm{~h}$, the remaining thionyl chloride was vacuum-distilled. The crude product was immediately used in the next synthetic step without further purification.

Yield: $18.3 \mathrm{~g}(98 \%) .{ }^{1} \mathrm{H}$ NMR $\left(\mathrm{CDCl}_{3}, \mathrm{ppm}, \delta\right)$ : $7.74(\mathrm{dd}, 1 \mathrm{H}) ; 7.48(\mathrm{~d}, 1 \mathrm{H}) ; 6.86(\mathrm{~d}, 1 \mathrm{H}) ; 4.17(\mathrm{dt}$, $4 \mathrm{H}) ; 3.90$ (q, $4 \mathrm{H}) ; 3.71(\mathrm{~m}, 4 \mathrm{H}) ; 3.67(\mathrm{~m}, 4 \mathrm{H}) ; 3.64$ $(\mathrm{s}, 4 \mathrm{H}) .{ }^{13} \mathrm{C} \mathrm{NMR}\left(\mathrm{CDCl}_{3}\right.$, ppm, $\left.\delta\right): 167.12 ; 155.23$; $148.51 ; 127.34 ; 125.29 ; 115.07 ; 111.85 ; 70.07$; $70.75 ; 70.66 ; 70.55 ; 69.27 ; 69.17 ; 69.09 ; 68.99$.

\section{3,4-Bis-(2-(2-(2-ethoxyethoxy)ethoxy) ethoxy)benzoyl Chloride}

This compound was prepared in a manner similar to that for 4-chlorocarbonylbenzo-18-crown-6 from 3,4-bis-(2-(2-(2-ethoxyethoxy)ethoxy)ethoxy) benzoic acid ( $35.5 \mathrm{~g}, 75 \mathrm{mmol}$ ), thionyl chloride, (21.9 mL, $300 \mathrm{mmol})$, and three drops of DMF.

Yield: quantitative. ${ }^{1} \mathrm{H}$ NMR $\left(\mathrm{CDCl}_{3}, \delta\right.$, ppm): $7.67(\mathrm{dd}, 1 \mathrm{H}) ; 7.48(\mathrm{~d}, 1 \mathrm{H}) ; 6.86(\mathrm{~d}, 1 \mathrm{H}) ; 4.13(\mathrm{dt}$, $4 \mathrm{H}) ; 3.79(\mathrm{~m}, 4 \mathrm{H}) ; 3.64(\mathrm{~m}, 4 \mathrm{H}) ; 3.55(\mathrm{~m}, 8 \mathrm{H})$; $3.47(\mathrm{~m}, 4 \mathrm{H}) ; 3.41(\mathrm{q}, 4 \mathrm{H}) ; 1.08(\mathrm{t}, 6 \mathrm{H}) .{ }^{13} \mathrm{C} \mathrm{NMR}$ $\left(\mathrm{CDCl}_{3}, \mathrm{ppm}, \delta\right): 166.85 ; 155.11 ; 148.33 ; 127.15$; $125.18 ; 115.71 ; 112.22 ; \quad 70.75 ; \quad 70.47 ; 69.59$; $69.37 ; 69.15 ; 68.89 ; 68.60 ; 66.38 ; 14.99$.

\section{4-(3', 5'-Dicarboxyfenilaminocarbonyl) benzo-18-crown-6}

4-Chlorocarbonyl-benzo-18-crown-6 (28.1 g, 75 mmol) was poured over a solution of $13.6 \mathrm{~g}$ (75 $\mathrm{mmol}$ ) of 5-aminoisophthalic acid in $70 \mathrm{~mL}$ of dimethylacetamide (DMA) under a blanket of nitrogen. The mixture was stirred for $30 \mathrm{~min}$ at room temperature, and then it was heated at $60{ }^{\circ} \mathrm{C}$ for $3 \mathrm{~h}$. After cooling to room temperature, the mixture was slowly poured into $500 \mathrm{~mL}$ of distilled water, and a pale yellow precipitate was formed. The product was filtered off and dried at $50{ }^{\circ} \mathrm{C}$. Finally, it was purified by solution/precipitation in DMA/water (four times).

Yield: $28.2 \mathrm{~g}(72 \%) . \mathrm{mp}:>300{ }^{\circ} \mathrm{C} .{ }^{1} \mathrm{H}$ NMR (DMSO- $\left.d_{6}, \mathrm{ppm}, \delta\right): 10.41(\mathrm{~s}, 1 \mathrm{H}) ; 8.67(\mathrm{~s}, 2 \mathrm{H})$; 8.21 (s, 1H); $7.64(\mathrm{dd}, 1 \mathrm{H}) ; 7.58(\mathrm{~d}, 1 \mathrm{H}) ; 7.08(\mathrm{~d}$, $1 \mathrm{H}) ; 4.17(\mathrm{~m}, 4 \mathrm{H}) ; 3.76(\mathrm{~m}, 4 \mathrm{H}) ; 3.58(\mathrm{~m}, 4 \mathrm{H})$; $3.52(\mathrm{~m}, 8 \mathrm{H}) .{ }^{13} \mathrm{C}$ NMR (DMSO- $d_{6}, \mathrm{ppm}, \delta$ ): $166.77 ; 165.32 ; 151.40 ; 147.70 ; 140.15 ; 131.76$; $126.31 ; 124.93 ; 121.57 ; 112.03 ; 111.95 ; 70.04$; $69.92 ; 69.84 ; 68.73 ; 68.60 ; 68.27$. EI-LRMS $\mathrm{m} / z$ : 519 (M+; 12); 431 (16); 339 (41); 252 (14); 251 (91); 181 (19); 180 (83); 165 (41); 164 (15); 163 (100); 137 (16); 135 (13); 79 (20).

Journal of Polymer Science: Part A: Polymer Chemistry DOI 10.1002/pola

\section{5-[3,4-Bis-(2-(2-(2-ethoxyethoxy)ethoxy) ethoxy)benzoylamino]isophthalic Acid}

This compound was prepared and purified in a manner similar to that for 4-(3',5'-dicarboxyfenilaminocarbonyl)benzo-18-crown-6 from 3,4-bis(2-(2-(2-ethoxyethoxy)ethoxy)ethoxy)benzoylchloride $(24.6 \mathrm{~g}, 50 \mathrm{mmol})$ and a solution of $9.1 \mathrm{~g}$ (50 mmol) of 5-aminoisophthalic acid in $65 \mathrm{~mL}$ of DMA.

Yield: $19.2 \mathrm{~g}(60 \%) .{ }^{1} \mathrm{H}$ NMR (DMSO- $d_{6}$, ppm, $\delta): 10.40(\mathrm{~s}, 1 \mathrm{H}) ; 8.66(\mathrm{~s}, 2 \mathrm{H}) ; 8.20(\mathrm{~s}, 1 \mathrm{H}) ; 7.65$ $(\mathrm{t}, 2 \mathrm{H}) ; 7.13(\mathrm{~d}, 1 \mathrm{H}) ; 4.19(\mathrm{~m}, 4 \mathrm{H}) ; 3.79(\mathrm{~m}, 4 \mathrm{H})$; $3.62(\mathrm{~m}, 4 \mathrm{H}) ; 3.44(\mathrm{~m}, 16 \mathrm{H}) ; 1.07$ (hex, $6 \mathrm{H}) .{ }^{13} \mathrm{C}$ NMR (DMSO- $d_{6}, \quad$ ppm, $\left.\delta\right): 166.62 ; 165.10$; $151.55 ; 147.71 ; 140.04 ; 131.64 ; 126.52 ; 113.28$; $112.79 ; 70.08 ; 69.90 ; 69.27 ; 68.99 ; 68.88 ; 68.49$; $68.28 ; 65.59 ; 15.15$. EI-LRMS m/z: 661 (19); 660 (54); 638 (M+; 16); 307 (17); 176 (15); 163 (12); 155 (26); 154 (100).

The overall synthetic steps for the monomers are shown in Schemes 1 and 2.

\section{Polymer Synthesis}

A typical polymerization reaction is described. In a 50-mL, three-necked flask fitted with a mechanical stirrer, $10 \mathrm{mmol}$ of diamine, $10 \mathrm{mmol}$ of diacid, and $1.4 \mathrm{~g}$ of lithium chloride were dissolved in a mixture of $6 \mathrm{~mL}$ of pyridine, $22 \mathrm{mmol}$ of TPP, and $20 \mathrm{~mL}$ of NMP. The solution was stirred and heated at $110{ }^{\circ} \mathrm{C}$ under a dry nitrogen blanket for $4 \mathrm{~h}$. As an insoluble gel was obtained under these conditions, the reaction was repeated with a higher NMP content, the quantities of the other chemicals being maintained, until a viscous solution was obtained. Then, the system was cooled at room temperature, and the solution was precipitated in $300 \mathrm{~mL}$ of methanol to render a swollen, fibrous precipitate. The obtained polymer was filtered off and washed with distilled water and acetone. Then, it was Soxhlet-extracted with acetone for $24 \mathrm{~h}$ and dried in a vacuum oven at $80{ }^{\circ} \mathrm{C}$ overnight. The yields were quantitative for all the polymers.

Polymers derived from 4-( $3^{\prime}, 5^{\prime}$-dicarboxyfenilaminocarbonyl)benzo-12-crown-4 (C4), 4-( $3^{\prime}, 5^{\prime}$ dicarboxyfenilaminocarbonyl)benzo-15-crown-5 (C5), 5-[3,4-bis-(2-ethoxyethoxy)benzoylamino] isophthalic acid (P4), and 5-[3,4-bis-(2-(2-ethoxy) ethoxy)benzoylamino]isophthalic acid monomer (P6) have been described previously. ${ }^{4,5}$

The polymer structures and acronyms are depicted in Scheme 3. 


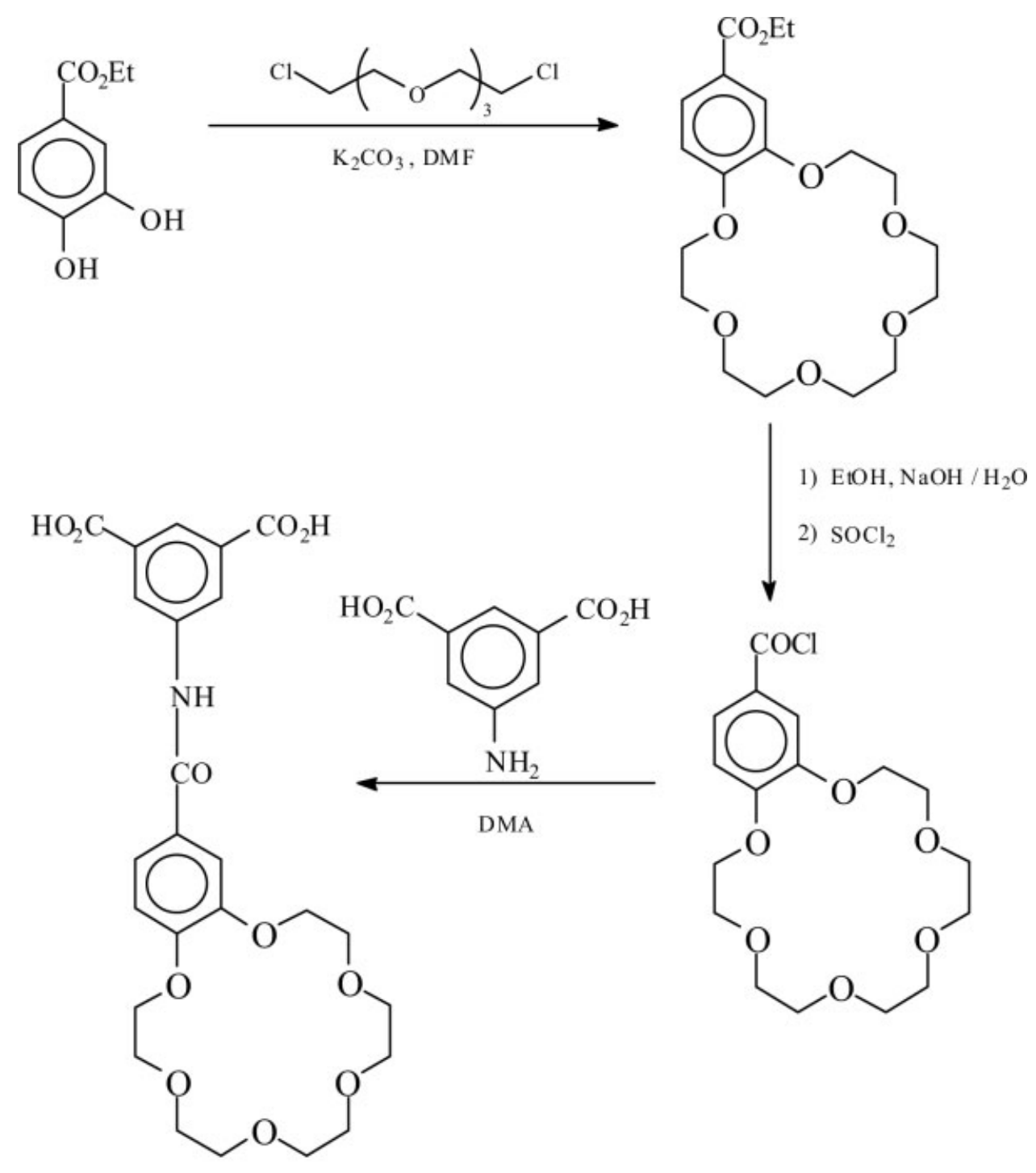

\section{C6}

Scheme 1. Experimental sequences for the synthesis of 4 -( $3^{\prime}, 5^{\prime}$-dicarboxyphenolaminocarbonyl)benzo-18-crown-6.

\section{Measurements and Instrumentation}

${ }^{1} \mathrm{H}$ and ${ }^{13} \mathrm{C}$ NMR spectra were recorded with a Varian Inova 400 spectrometer operating at 399.92 and $100.57 \mathrm{MHz}$, respectively, with $\mathrm{CDCl}_{3}$ or DMSO- $d_{6}$ as the solvent.

EI-LRMS spectra were obtained at $70 \mathrm{eV}$ on an Agilent 6890N mass spectrometer. High-resolution mass spectrometry was carried out on a Micromass AutoSpect Waters mass spectrometer.

Fourier transform infrared (FTIR) spectra were recorded with a Nicolet Impact spectrometer.

Elemental analyses were performed on a Leco CHNS-932 microanalyzer.
The inherent viscosities were measured with an Ubbelohde viscometer at $25 \pm 0.1{ }^{\circ} \mathrm{C}$ with NMP as a solvent at a $0.5 \mathrm{~g} / \mathrm{dL}$ concentration.

Differential scanning calorimetry (DSC) data were recorded on a PerkinElmer Pyris I analyzer from a $10-\mathrm{mg}$ sample under a nitrogen atmosphere at a scanning rate of $20{ }^{\circ} \mathrm{C} / \mathrm{min}$. Thermogravimetric analysis (TGA) data were recorded under a nitrogen or oxygen atmosphere on a Mettler-Toledo TGA \SBTA851 analyzer from a 5-mg sample at a scanning rate of $10{ }^{\circ} \mathrm{C} / \mathrm{min}$.

The polymer solubility was determined by the mixing of $10 \mathrm{mg}$ with $1 \mathrm{~mL}$ of the solvent, 


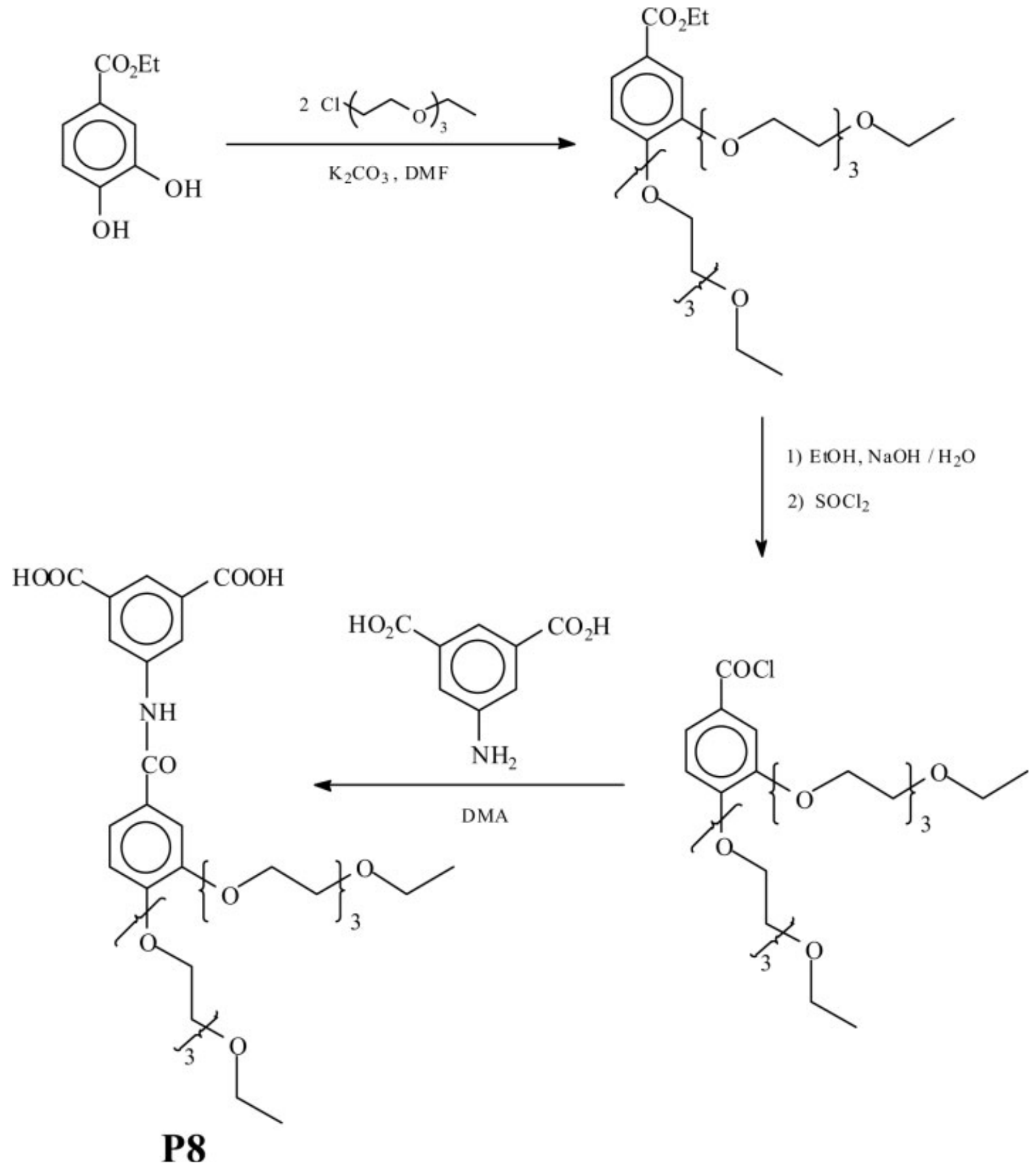

Scheme 2. Experimental sequences for the synthesis of 5-[3,4-bis-(2-(2-(2-ethoxyethoxy)ethoxy)ethoxy)benzoylamino]isophthalic acid.

followed by stirring for $24 \mathrm{~h}$ at room temperature.

Polymer films were prepared by the evaporation of cast solutions in DMA. In most cases, a concentration of $10 \%$ by polymer weight was used, and the solvent was eliminated through heating at $100{ }^{\circ} \mathrm{C}$ for $4 \mathrm{~h}$ in an air-circulating oven and then at $120{ }^{\circ} \mathrm{C}$ for $4 \mathrm{~h}$ in vacuo ( 1 $\mathrm{mmHg}$ ). To determine the tensile properties of the polymers, strips ( $5 \mathrm{~mm}$ wide and $30 \mathrm{~mm}$ long) were cut from polymer films $30-100 \mu \mathrm{m}$ thick and tested on an MTS Synergie 200 universal testing dynamometer at $20^{\circ} \mathrm{C}$. Mechanical clamps were used, and an extension rate of $5 \mathrm{~mm} / \mathrm{min}$ was applied with a gauge length of $10 \mathrm{~mm}$. At least six samples were tested for each polymer, and the data was then averaged out. The degrees of crystallinity of the polymer films were evaluated with 

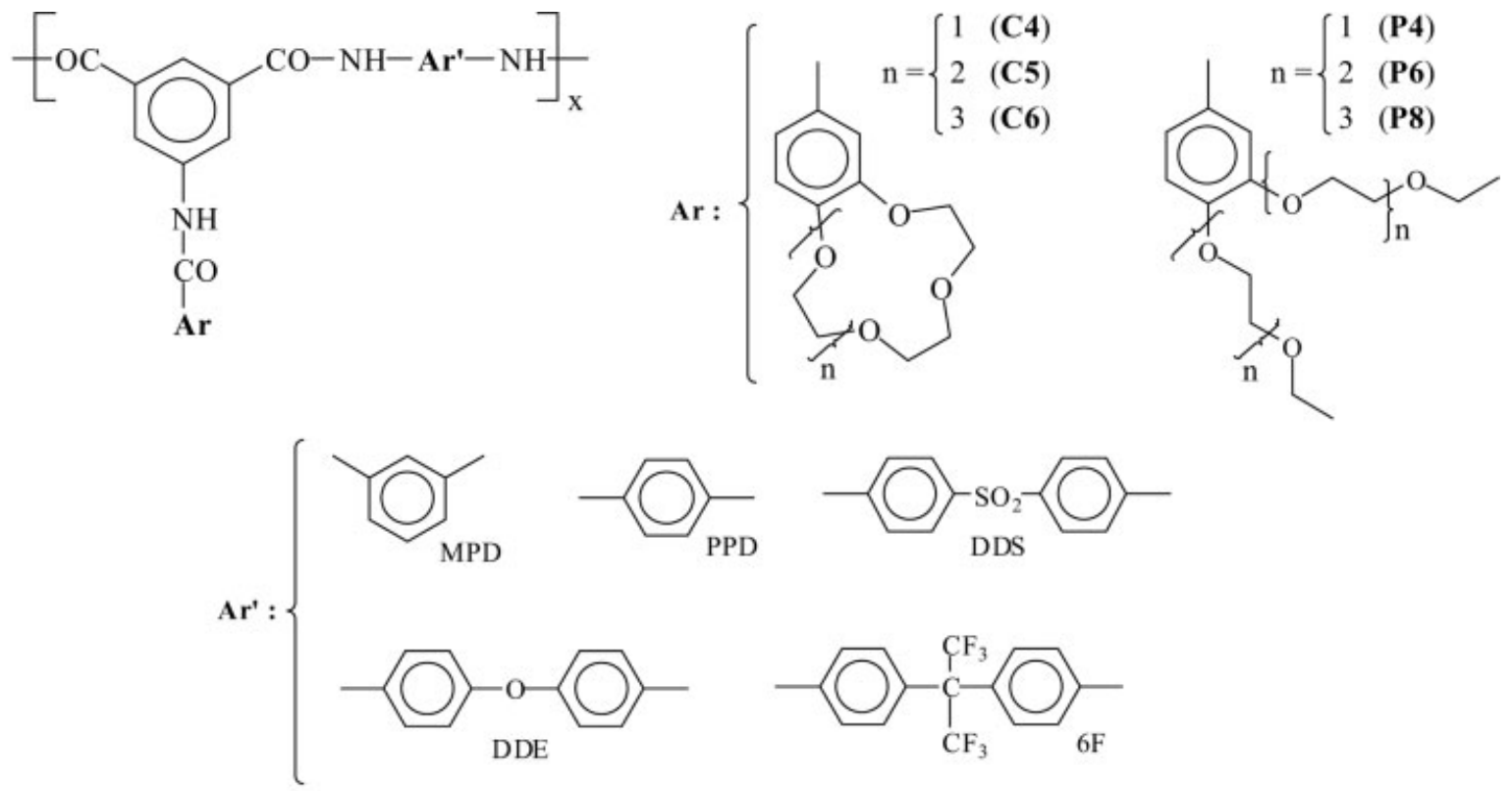

\begin{tabular}{|c|c|c|c|c|c|c|c|c|c|}
\hline & \multicolumn{3}{|c|}{ Series $1(n=1)$} & \multicolumn{3}{|c|}{ Series $2(n=2)$} & \multicolumn{3}{|c|}{ Series $3(n=3)$} \\
\hline & Polymer & Ar & Ar' & Polymer & Ar & Ar' & Polymer & Ar & Ar' \\
\hline \multirow{5}{*}{$\begin{array}{l}\text { Crown } \\
\text { Family }\end{array}$} & C4MPD & $\mathrm{C} 4$ & MPD & C5MPD & $\mathrm{C} 5$ & MPD & C6MPD & C6 & MPD \\
\hline & C4PPD & $\mathrm{C} 4$ & PPD & C5PPD & $\mathrm{C} 5$ & PPD & C6PPD & C6 & PPD \\
\hline & C4DDS & $\mathrm{C} 4$ & DDS & C5DDS & $\mathrm{C} 5$ & DDS & C6DDS & C6 & DDS \\
\hline & C4DDE & $\mathrm{C} 4$ & DDE & C5DDE & C5 & DDE & C6DDE & C6 & DDE \\
\hline & $\mathrm{C} 4 / 6 \mathrm{~F}$ & $\mathrm{C} 4$ & $6 \mathrm{~F}$ & $\mathrm{C} 5 / 6 \mathrm{~F}$ & C5 & $6 \mathrm{~F}$ & $\mathrm{C} 6 / 6 \mathrm{~F}$ & C6 & $6 \mathrm{~F}$ \\
\hline \multirow{5}{*}{$\begin{array}{l}\text { Dipodal } \\
\text { Family }\end{array}$} & P4MPD & P4 & MPD & P6MPD & P6 & MPD & P8MPD & P8 & MPD \\
\hline & P4PPD & P4 & PPD & P6PPD & P6 & PPD & P8PPD & P8 & PPD \\
\hline & P4DDS & P4 & DDS & P6DDS & P6 & DDS & P8DDS & P8 & DDS \\
\hline & P4DDE & P4 & DDE & P6DDE & P6 & DDE & P8DDE & P8 & DDE \\
\hline & $\mathrm{P} 4 / 6 \mathrm{~F}$ & P4 & $6 \mathrm{~F}$ & $\mathrm{P} 6 / 6 \mathrm{~F}$ & P6 & $6 \mathrm{~F}$ & $\mathrm{P} 8 / 6 \mathrm{~F}$ & P8 & $6 \mathrm{~F}$ \\
\hline
\end{tabular}

Scheme 3. Chemical structures and acronyms of the polyamides.

a Philips X-Pert X-ray diffractometer operating at $40 \mathrm{kV}$ with $\mathrm{Co}$ as a radiation source and a graphite filter. The scans were obtained with a scan step size of 0.0258 and a scan step time of $0.5 \mathrm{~A}$ The morphologies of the polymer films, previously coated with a gold film, were analyzed by scanning electron microscopy (SEM) with a JEOL model 5310 scanning microscope operating under a low vacuum at $20 \mathrm{kV}$.

Water sorption measurements were determined gravimetrically at room temperature.
Powdered polymeric samples of about $300 \mathrm{mg}$, previously dried at $120{ }^{\circ} \mathrm{C}$ for 24 over phosphorus pentoxide, were placed in a closed box containing a saturated aqueous solution of $\mathrm{NaNO}_{2}$ at $20{ }^{\circ} \mathrm{C}$, which provided a relative humidity of $65 \%$. The samples were periodically weighed over a period of $24 \mathrm{~h}$ and were then allowed to remain in contact with this atmosphere for a further 8 days until they had equilibrated with their surroundings and presented no further changes in weight. 
The matrix-assisted laser desorption/ionization time-of-flight mass spectrometry (MALDI-TOF) mass spectra were recorded with a Brucker Biflex III in the reflectron mode. A nitrogen laser with a wavelength of $337 \mathrm{~nm}$ was used for irradiation together with an acceleration voltage of $20 \mathrm{kV}$. The irradiation targets were prepared with dithranol as the matrix and potassium trifluoroacetate as the dopant. The samples were dissolved in a mixture of chloroform and trifluoroethanol (1/1).

The permeability of the $\mathrm{HCl}$ solutions was measured with a previously reported system. ${ }^{7}$ This consisted of two 250-mL cells filled with a surfactant solution (A) and water (B). These were connected by two 7-mm-radius horizontal tubes, with the polymer membrane sealed, with silicone, between these two tubes. Control experiments were performed to ensure that there was no silicone in the permeation area and that mass transport occurred only at the polymer-solution interface. To prevent any contribution from the hydrostatic pressure to the mass flux, cell A was filled with $200 \mathrm{~mL}$ of the $\mathrm{HCl}$ solution, and the other cell was filled with $200 \mathrm{~mL}$ of water. The change in the ionic solute concentration in cell $\mathrm{B}$ was determined during the permeability experiment by the measurement of the electrical conductivity with a YSI 3200 instrument. This was calibrated before each experiment with at least five freshly prepared solutions of $\mathrm{HCl}$ with different concentrations. These were prepared by dilutions from a concentrated $\mathrm{HCl}$ solution (32\% from Riedel deHäen). The accurate concentrations were obtained by volumetric titration with sodium tetraborate (Sigma-Aldrich; 99\%). The same conditions were used for calibration and permeability experiments. A constant temperature $\left( \pm 0.1{ }^{\circ} \mathrm{C}\right)$ was maintained by the immersion of the system in a thermostat bath (Multistirrer 6, Velp Scientifica). Solutions in both cells were stirred at about $200 \mathrm{rpm}$ to reduce the Nernst layer in the membrane-solution interface and to increase the reproducibility of the conductivity sensor.

The permeability of ionic solutes through the polymeric membranes can be described in terms of mutual diffusion with boundary and initial conditions $[C(0, t)=C, C(l, t)=0$, and $C(x, 0)=0$ (where $C$ is the $\mathrm{HCl}$ concentration in the membrane)]:

$$
\partial C / \partial t=\partial / \partial x(D \partial C / \partial x)
$$

This results in simple formulas for the calculation of the permeability coefficient $(P)$ and diffu- sion coefficient $(D)$ :

$$
\begin{aligned}
& P=J l / c \\
& D=l^{2} /(6 \theta)
\end{aligned}
$$

where $l$ is the thickness of the polymeric membrane measured after each experiment at $25{ }^{\circ} \mathrm{C}$ with a Helias micrometer $( \pm 0.001 \mathrm{~mm}), J$ is the steady-state flux through the membrane, $\theta$ is the time lag, and $c$ is the bulk $\mathrm{HCl}$ concentration.

\section{RESULTS AND DISCUSSION}

This work describes the properties and synthesis of polyamides bearing crown ethers and their dipodal counterparts. The aim of this work is to compare the behavior and properties of polyamides derived from these monomers, which offer the novelty of their chemical structures and the possibility of comparing the property differences imparted by a pendant crown ether cyclic structure and its corresponding open-chain form while maintaining the chemical characteristics of the oxyethylene sequences.

The crown ether moieties are benzo-12-crown4, benzo-15-crown-5, and benzo-18-crown- 6 . The syntheses of polyamides bearing benzo-12-crown4, benzo-15-crown-5, and their dipodal open-chain counterparts are described elsewere. ${ }^{4,5}$

The polyamides bearing benzo-18-crown- 6 and their dipodal counterparts have been synthesized through the combination of five commercial diamines with two new diacid monomers (see Schemes 1 and 2 for the monomer structures and syntheses). The intermediates and the monomers were characterized with IR and ${ }^{1} \mathrm{H}$ and ${ }^{13} \mathrm{C}$ NMR spectroscopy, and the chemical structures of all the products were fully confirmed.

The structures of the polymers described here are shown in Scheme 3, and the polymerization conditions, inherent viscosities, and elemental analyses are given in Table 1 . As an illustrative example, Figure 1 shows the chemical characterization of polymer C6DDE. The polymers derived from $\mathrm{C} 6$ and $\mathrm{P} 8$ diacid monomers were synthesized according to the method described by Yamazaki et al., ${ }^{8}$ but with differences in the initial diamine and diacid concentrations (i.e., $0.5 \mathrm{~mol}$ of each monomer/L of NMP under standard conditions). In all the polymers derived from $\mathrm{C} 6$ and $\mathrm{P} 6$, the initial diamine and diacid concentration 
Table 1. Inherent Viscosities, Polymerization Conditions, and Elemental Analysis of the Polyamides

\begin{tabular}{|c|c|c|c|c|c|c|c|c|c|c|}
\hline \multirow[b]{2}{*}{ Polymer } & \multirow{2}{*}{$\begin{array}{l}\text { Inherent } \\
\text { Viscosity } \\
\left(\mathrm{dL} \mathrm{g} \mathrm{g}^{-1}\right)\end{array}$} & \multirow[b]{2}{*}{$\mathrm{IDC}^{\mathrm{a}}$} & \multicolumn{4}{|c|}{ Theoretical } & \multicolumn{4}{|c|}{ Found } \\
\hline & & & $\mathrm{C}(\%)$ & $\mathrm{H}(\%)$ & $\mathrm{N}(\%)$ & $\mathrm{S}(\%)$ & $\mathrm{C}(\%)$ & $\mathrm{H}(\%)$ & $\mathrm{N}(\%)$ & $\mathrm{S}(\%)$ \\
\hline C6MPD & 1.49 & 0.125 & 62.94 & 5.62 & 7.10 & - & 62.66 & 5.80 & 6.87 & - \\
\hline C6PPD & 0.79 & 0.330 & 62.94 & 5.62 & 7.10 & - & 62.73 & 5.81 & 6.89 & - \\
\hline C6DDS & 0.88 & 0.250 & 60.73 & 5.10 & 5.74 & 4.38 & 60.50 & 5.36 & 5.52 & 4.10 \\
\hline C6DDE & 0.40 & 0.143 & 65.00 & 5.45 & 6.15 & - & 64.75 & 5.67 & 6.04 & - \\
\hline $\mathrm{C} 6 / 6 \mathrm{~F}$ & 1.10 & 0.125 & 58.75 & 4.56 & 5.14 & - & 58.66 & 4.72 & 4.96 & - \\
\hline P8MPD & 0.43 & 0.125 & 62.61 & 6.67 & 5.92 & - & 60.32 & 6.89 & 5.64 & - \\
\hline P8PPD & 1.49 & 0.083 & 62.61 & 6.67 & 5.92 & - & 62.51 & 6.79 & 5.70 & - \\
\hline P8DDS & 1.26 & 0.330 & 60.77 & 6.05 & 4.94 & 3.77 & 60.55 & 5.99 & 4.76 & 3.52 \\
\hline P8DDE & 1.01 & 0.072 & 64.41 & 6.41 & 5.24 & - & 64.22 & 6.65 & 5.01 & - \\
\hline $\mathrm{P} 8 / 6 \mathrm{~F}$ & 1.21 & 0.125 & 59.03 & 5.49 & 4.49 & - & 58.75 & 5.67 & 4.20 & - \\
\hline
\end{tabular}

${ }^{a}$ Initial diamine and diacid concentration [moles of diamine or diacid/volume of NMP $\left.(\mathrm{L})\right]$ in the polymerization reaction of the polyamides. The IDC for standard Yamazaki conditions is $0.5 \mathrm{M}$. The polymerizations were carried out with $10 \mathrm{mmol}$ of diamine, $10 \mathrm{mmol}$ of diacid, and $1.4 \mathrm{~g}$ of lithium chloride, which were dissolved in a mixture of $6 \mathrm{~mL}$ of pyridine, $22 \mathrm{mmol}$ of TPP, and the proper quantity of NMP.

was lower than $0.5 \mathrm{M}$. When an initial diamine and diacid concentration of $0.5 \mathrm{M}$ was employed, insoluble gels were obtained. The initial diamine and diacid concentration was therefore reduced to obtain soluble polymers with higher inherent viscosities. Data for the relationship between the inherent viscosities and initial diamine and diacid concentration is depicted in Figure 2 for polyamides with pendant crown ether moieties.

The tendencies to give polyamide gels under standard Yamazaki conditions were also observed in all the polyamides derived from C5 and some of the polymers derived from P6 diacid monomers, but not in the polymers derived from $\mathrm{C} 4$ and $\mathrm{P} 4 .{ }^{4,5}$ Thus, the propensity to produce a gel increases with an increment in the oxyethylene sequences in crown or podal substructures.

Because of the small cavity of 15-crown- 5 and 18-crown-6, the gel phenomenon cannot be attributed to the threading through the crown cavity. The gelation of polymers bearing dipodal structures and previous experiments with model compounds support this idea. ${ }^{5}$ Moreover, the polymerizations of methacrylates bearing 12-crown$4,{ }^{9}$ 15-crown-5, 18-crown-6, benzo-12-crown-5, benzo-15-crown-5, and benzo-18-crown- $6^{10}$ give soluble polymethacrylates. Furthermore, the polymerization of a diamine monomer containing a benzo-15-crown-5 moiety with different diacid dichlorides and dianhydrides under low-temperature polymerization conditions leads to soluble aromatic polyamides and polyimides. ${ }^{11}$ However, the threading through the crown cavity has been proposed for gelation in polymers with higher membered crown ether ring moieties. ${ }^{12-14}$

In principle, the gel, or physical network, could be attributed to the threading of cyclic polyamides or oligoamides by segments of another polymer chain during polymerization to yield polyrotaxanes or polycatenanes.

As stated by Kricheldorf and coworkers, ${ }^{15-21}$ the kinetically controlled step-growth polymerization tends to yield cyclic species as stable end products. On the basis of this, Gibson et al. ${ }^{22}$ indicated the possible formation of polyrotaxanes, catenanes, and polycatenanes due to cyclization in the polymerization reaction. The highmembered ring cycles can first form branched polyamides that can finally progress to networks because of crosslinked catenate species.

With the procedure described in a previous work, ${ }^{5}$ soluble polymers were obtained by the reduction of the initial monomer concentration (initial diamine and diacid concentration) in the synthetic procedure. The common ratio in the Yamazaki method-diacid (10 mmol)/diamine (10 $\mathrm{mmol}) / \mathrm{LiCl} \quad(1.4 \mathrm{~g}) /$ pyridine $\quad(6 \mathrm{~mL}) / \mathrm{TPP} \quad(22$ mmol)/NMP (20 mL) - was altered by an increase in the NMP content. Table 1 shows the initial diamine and diacid concentrations employed for the polymer synthesis for polyamides derived from $\mathrm{C} 6$ and $\mathrm{P} 8$ diacid monomers.

The use of an initial diamine and diacid concentration lower than $0.5 \mathrm{M}$ has two effects. First, the cyclization is favored at the expense of chain growth, and the average molecular weight 

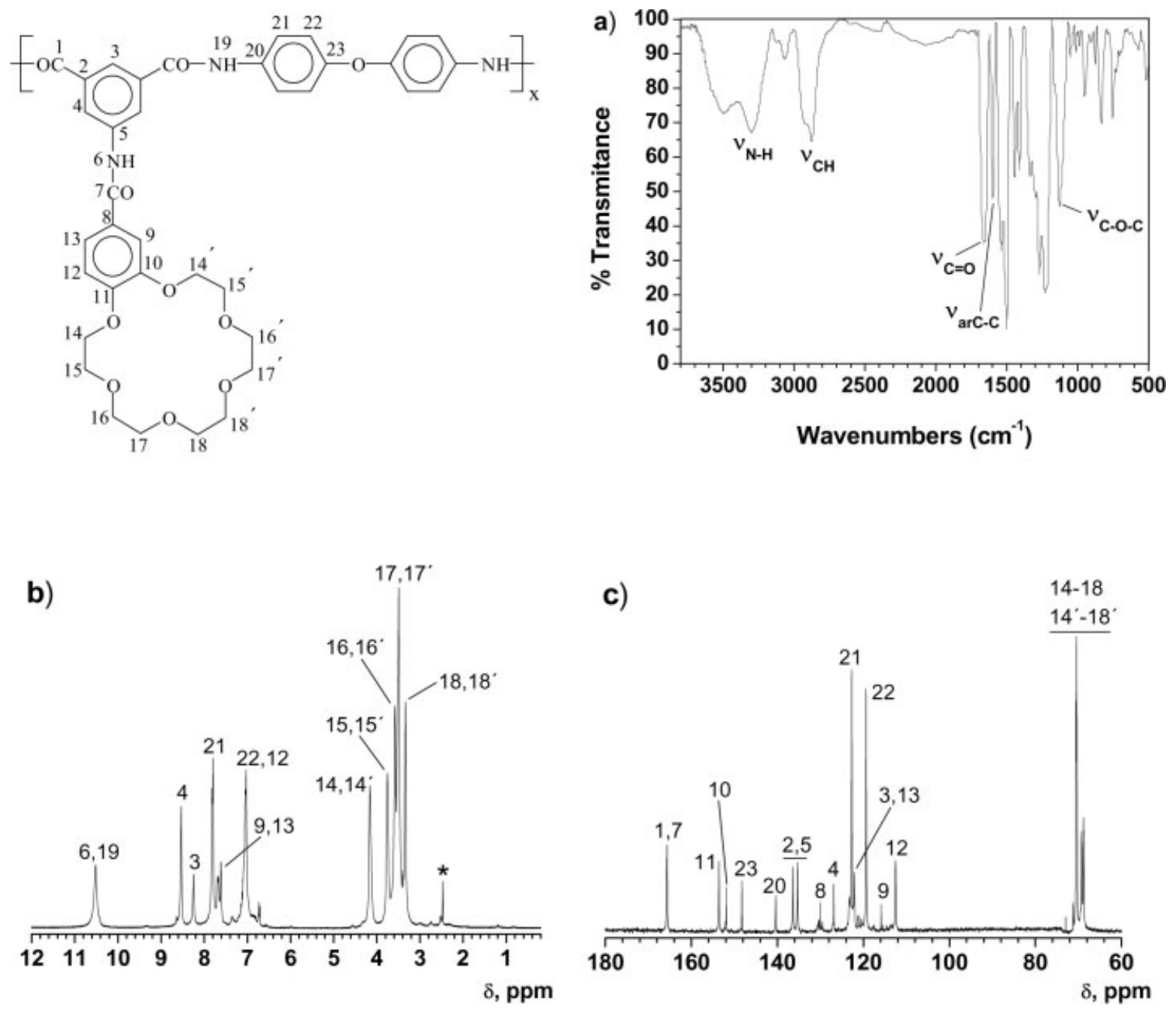

Figure 1. Characterization of polyamide C6DDE: (a) FTIR, (b) ${ }^{1} \mathrm{H}$ NMR, and (c) ${ }^{13} \mathrm{C}$ NMR.

will decrease. Second, the reduction of the concentrations of all species and lower molecular weights reduce the probability of catenanization.

If the cyclic oligoamides are the species responsible for gel development through polycatenane formation, it is worth considering the influence of the ring size of the pendant crown ether on the tendency of the polyamides to cyclize. The trend of forming gels during polymerization is much higher in the polyamides derived from the benzo-18crown- 6 containing monomer than in those from the monomer bearing a benzo-15-crown-5 substructure. With respect to polyamides with benzo12-crown-4 moieties, gel formation under standard Yamazaki conditions was not observed, and instead soluble, high-molecular-weight polyamides were obtained. ${ }^{4}$ In relation to polymers with dipodal substructures, all those derived from P8 diacid gave gels under standard Yamazaki conditions, but gel formation was observed with only one of the polymers derived from P6 and with none of the ones derived from $\mathrm{P} 4$.

For the qualitative estimation of the influence of the polymer structure on the rate of cyclization $\left(V_{\text {cy }}\right)$, eq 4 was proposed by Kricheldorf et al.: ${ }^{15}$

$$
V_{\mathrm{cy}} \approx \frac{N_{\mathrm{fc}}}{N_{\mathrm{uc}}}
$$

where $N_{\mathrm{fc}}$ and $N_{\mathrm{uc}}$ are the number of chain conformations that favor cyclization and the number of chain conformations that are unfavorable for cyclization, respectively. If the trend to gelation is related to the cycle content, the increase in the lateral volume of the podal and crown moieties with the increment of the oxyethylene sequences and the interaction of the solvent with the oxyethylene sequences during polymerization could be responsible for an $N_{\mathrm{fc}} / N_{\mathrm{uc}}$ ratio increment. 


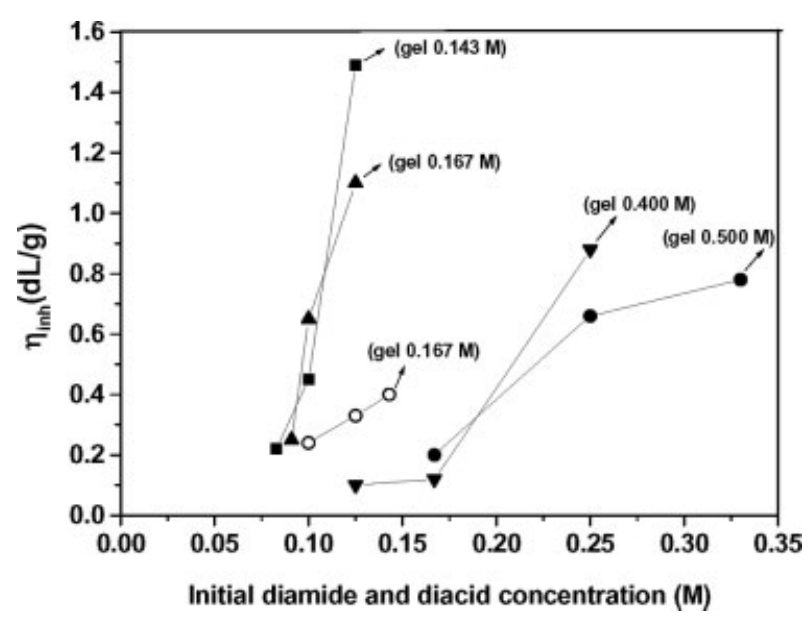

Figure 2. Inherent viscosity $\left(\eta_{\text {inh }}\right)$ versus the initial diamine and diacid concentration [moles of diamine or diacid/volume of NMP $(\mathrm{L})$ ] in the polymerization reactions of polyamides that give rise to gels under standard Yamazaki polymerization conditions : (ם) C6MPD,

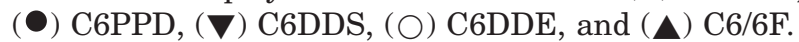

Figure 3 depicts one of the conformations of the cyclic polyamide (C5PPD) with a polymerization degree of 20 . The modeled ${ }^{23}$ conformer is circular and has alternating up and down ether moieties with a cavity diameter of about $75 \AA$. Although many cyclic conformations can be proposed, most of them have cavities with radii that are big enough to allow threading.

As the Yamazaki method is not a clean reaction, ${ }^{24,25}$ catenanization via the crown ether rings could in principle not be the only reason for gelation; other side reactions could also be responsible for the crosslinking. This fact is discussed in a previous article ${ }^{5}$ and has been disregarded because side reactions have not been detected in the synthesis of model compounds and because the crosslinking phenomenon is observed only in the polymerization of some monomers, whereas all of them have the same amide and ether linkages as functional groups. As the same functional groups are supposed to render similar reactions, it is improbable that an increasing number of ether groups in the lateral chain could lead to new side reactions.

\section{Analyses of the Cyclic Forms}

To get insight into the cyclic or acyclic polymer structure, MALDI-TOF mass spectra were obtained from P8MPD and C6MPD polymer samples of different inherent viscosities.
The mass spectra of both the P8MPD and C6MPD series show, as expected, ${ }^{15-21}$ that cyclic forms are predominant and detectable up to approximately $6000 \mathrm{Da}$ and up to a polymerization degree of 8. (Figs. 4 and 5). P8MPD (Fig. 4) indicates almost exclusively cycles, but the C6MPD derivatives show two series of linear species ( $\mathrm{La}$ and $\mathrm{Lb}$ in Fig. 5) in addition to the predominant cyclic forms.

In summary, the extracted soluble polyamides of different viscosities (C6MPD and P8MPD) show that in all samples cyclic forms are predominant up to a polymerization degree of 8 . It was not possible to detect cycles with a higher polymerization degree. One reason may be technical limitations in the measurement or the involvement of higher cycles in the buildup of crosslinked rotaxanes or catenanes, whereas the lower cyclic forms lack the ability to thread onto polyamide chains. This idea may be extrapolated to other polyamides of polymer series 3 (see Scheme 3).

\section{Thermal Properties}

The thermal behavior of the polymers has been evaluated with DSC and TGA.

The glass-transition temperatures $\left(T_{\mathrm{g}}{ }^{\prime} \mathrm{s}\right)$ of the polymers derived from the $\mathrm{C} 6$ and $\mathrm{P} 8$ diacid monomers varied between 176 and $307^{\circ} \mathrm{C}$ (Table 2).

Comparing the $T_{\mathrm{g}}$ values of the polymer series and families (Fig. 6) and considering the diacid residue of the polymeric structural unit,

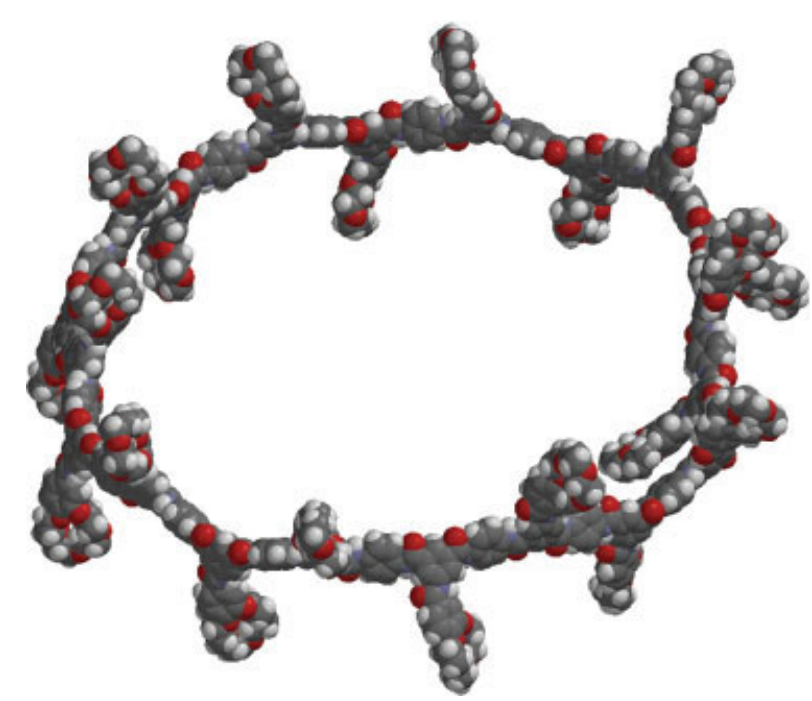

Figure 3. Cyclic polyamide (C5PPD) with a polymerization degree of 20 . [Color figure can be viewed in the online issue, which is available at www. interscience.wiley.com.]

Journal of Polymer Science: Part A: Polymer Chemistry 


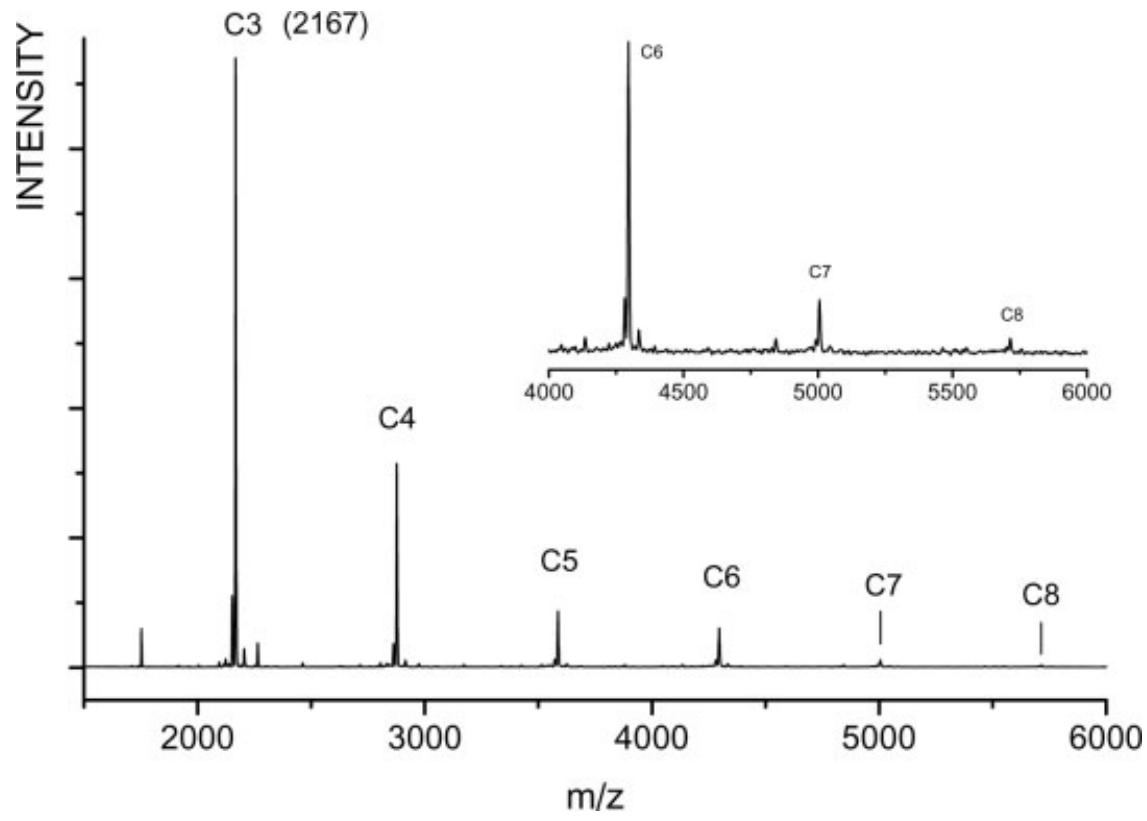

Figure 4. MALDI-TOF mass spectrum of polyamide P8MPD displaying mass peaks of cycles (represented by symbol C) up to a polymerization degree of $=8$.

we have observed the following $T_{\mathrm{g}}$ trends: increasing the pendant cycle size or the podal arms decreases $T_{\mathrm{g}}$, with $T_{\mathrm{g}}$ of the crown polyamides being much higher than $T_{\mathrm{g}}$ of the polymers with dipodal side groups. The increase in the number of oxyethylene sequences of the crown or podal moieties increases the interchain distances. Furthermore, the higher conformational mobility of higher ring-member cycles or longer dipodal arms increases the interaction of the ether groups with the amides. These two facts diminish the density of interchain amide-amide hydrogen

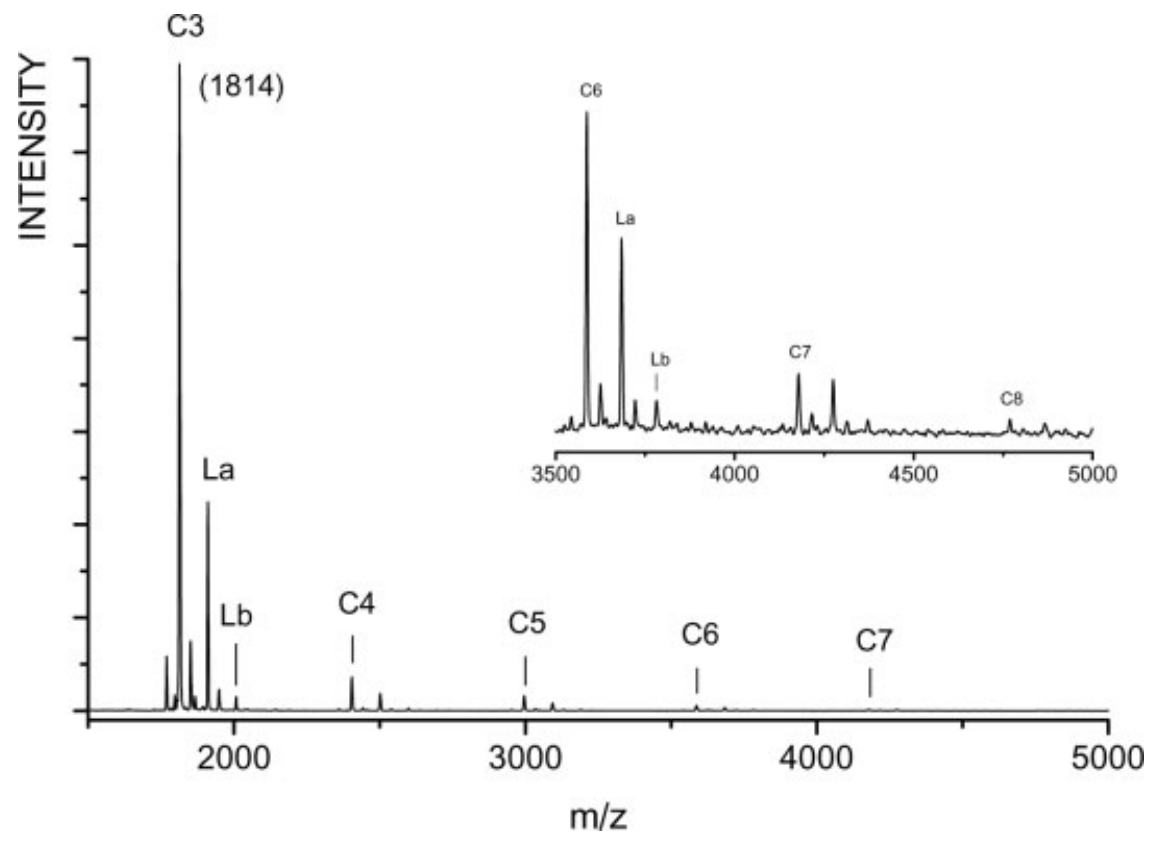

Figure 5. MALDI-TOF mass spectrum of polyamide C6MPD displaying mass peaks of cycles (represented by symbol C) up to a polymerization degree of $=8$. La and $\mathrm{Lb}$ represent different linear species. 
Table 2. Thermal Properties and Solubility of the Polyamides Derived from the C6 and P8 Diacid Monomers

\begin{tabular}{|c|c|c|c|c|c|c|c|c|}
\hline \multirow[b]{2}{*}{ Polymer } & \multicolumn{2}{|c|}{$\begin{array}{c}\text { Thermal } \\
\text { Properties }\end{array}$} & \multicolumn{6}{|c|}{ Solubility $^{\mathrm{a}}$} \\
\hline & $T_{\mathrm{g}}\left({ }^{\circ} \mathrm{C}\right)$ & $T_{\mathrm{d}}\left({ }^{\circ} \mathrm{C}\right)$ & $\mathrm{DMF}$ & DMA & NMP & DMSO & Tetrahydrofuran & $p$-Cresol \\
\hline C6MPD & 226 & 405 & ++ & ++ & ++ & + & + & ++ \\
\hline C6PPD & 307 & 390 & + & ++ & ++ & ++ & - & + \\
\hline C6DDS & 270 & 405 & ++ & ++ & ++ & ++ & - & ++ \\
\hline C6DDE & 234 & 410 & + & ++ & ++ & + & - & + \\
\hline $\mathrm{C} 6 / 6 \mathrm{~F}$ & 231 & 415 & ++ & + & ++ & +- & - & + \\
\hline P8MPD & 193 & 400 & ++ & ++ & ++ & ++ & + & ++ \\
\hline P8PPD & 185 & 400 & ++ & ++ & ++ & ++ & - & + \\
\hline P8DDS & 176 & 410 & ++ & ++ & ++ & ++ & - & ++ \\
\hline P8DDE & 182 & 405 & ++ & ++ & ++ & ++ & + & ++ \\
\hline $\mathrm{P} 8 / 6 \mathrm{~F}$ & 185 & 395 & + & ++ & ++ & + & - & ++ \\
\hline
\end{tabular}

$\mathrm{a}_{++}=$soluble at room temperature $+=$soluble on heating; $+-=$partially soluble; $-=$insoluble

bonds and thus the cohesive energy, lowering $T_{\mathrm{g}}$. The $T_{\mathrm{g}}$ differences between crown polymers and polyamides with equivalent open-chain counterparts arise from the higher conformational mobility of the ether groups present in the podand moieties, which facilitates interactions with the amide groups because of hydrogen bonding. This in turn diminishes the density of the interchain amideamide hydrogen bonds, thereby lowering $T_{\mathrm{g}}$. Plasticization by the podal arms is also likely to contribute to a lower $T_{\mathrm{g}}$ value. $^{26}$

The expected trend in the glass transition with the nature of the diamine has been observed.

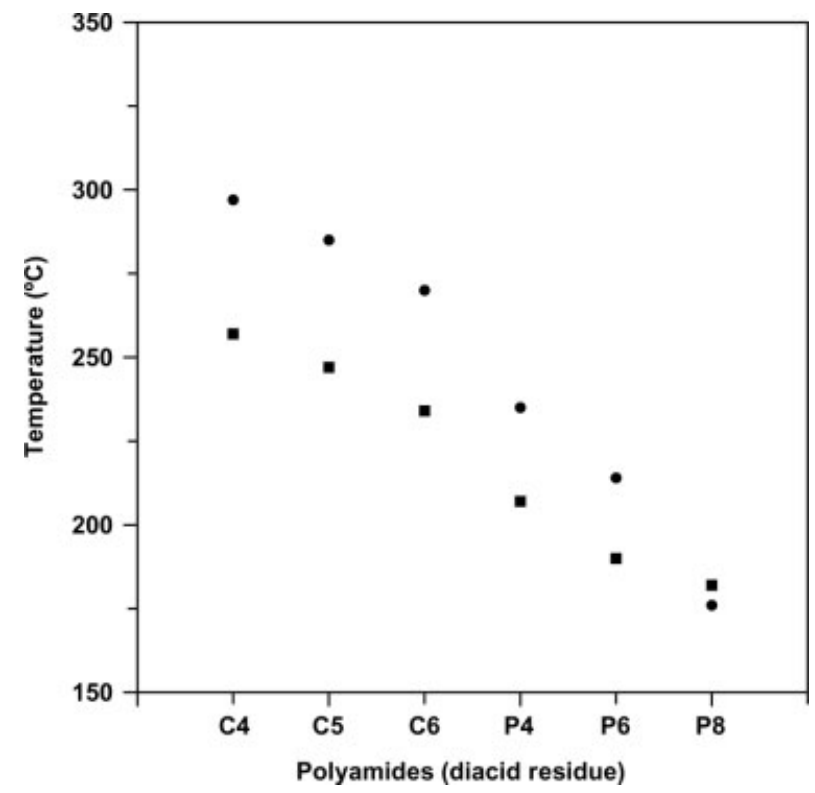

Figure 6. $T_{\mathrm{g}}$ of two families of polyamides derived from diamines $(\bullet)$ DDS and ( $\square$ ) DDE.
In each polyamide series, $T_{\mathrm{g}}$ decreases in the order of $\mathrm{PPD}>\mathrm{DDS}>6 \mathrm{~F}>\mathrm{DDE}$, which agrees with previous studies. The $T_{\mathrm{g}}$ 's of polyamides derived from MPD lie between the values for PPD and DDE. ${ }^{4,5,27,28}$

The thermal resistance, in terms of the initial decomposition temperature $\left(T_{\mathrm{d}}\right)$, was evaluated with TGA. The thermal stability under $\mathrm{N}_{2}$ is fairly high, ranging from 390 to $415{ }^{\circ} \mathrm{C}$ for polymers derived from C6 and P8 diacid monomers (Table 2). For polyamides derived from C4, C5, $\mathrm{P} 4$, and $\mathrm{P} 6$, the $T_{\mathrm{d}}$ values are also all close to $400{ }^{\circ} \mathrm{C}$. The small differences in $T_{\mathrm{d}}$ can be attributed to the fact that in all cases the decomposition starts with the thermal cleavage of the $\mathrm{C}-\mathrm{C}$ or $\mathrm{C}-\mathrm{O}$ bonds of the aliphatic oxyethylene sequences. ${ }^{28}$

\section{Wide-Angle X-Ray Scattering (WAXS)}

The crystallinity of the polyamides was evaluated with DSC and WAXS. No endothermic peak was observable with DSC, and an amorphous pattern was recorded with WAXS in all cases. Figure 7 shows the WAXS patterns of C6PPD and P8PPD, representative polymers of the crown and podal polyamide families, respectively. Thus, the family of polyisophthalamides reported here can be considered to be amorphous materials with good thermal resistance and very high $T_{\mathrm{g}}$ 's.

The amorphous X-ray diffraction halo is related to the intermolecular interference. Thus, its position is dependent on the degree of packing of molecules in the amorphous phase: the smaller 


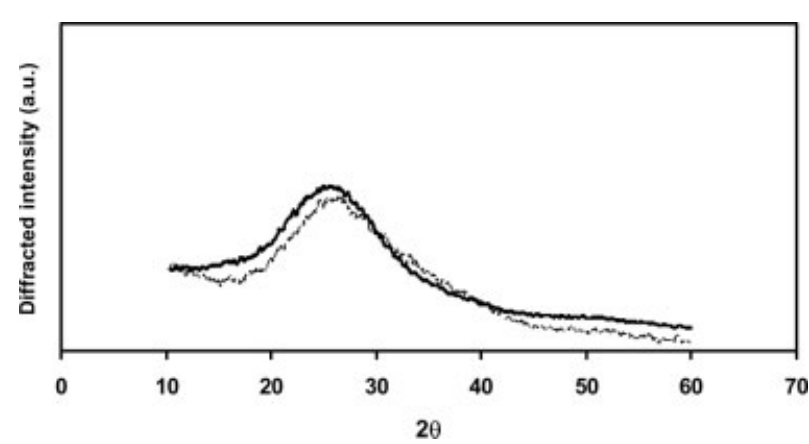

Figure 7. X-ray diffraction patterns of (-) C6PPD and (- - -) P8PPD.

the angle is, the higher the intermolecular distance is. ${ }^{29}$ Figure 8 shows the X-ray diffraction patterns of C4PPD, C5PPD, and C6PPD. The increase in the number of ethylene oxide from 12crown- 4 to 18-crown- 6 brings about a displacement of the amorphous halo to higher diffraction angles, which implies an incremental increase in the interchain polymer distance. Higher interchain distances mean a lower density of hydrogen bonds and so lower cohesive energy, and this agrees with the trends in $T_{\mathrm{g}}$.

The interchain distances do not follow the same trend as the polymers with dipodal moieties. The increment in the ethylene oxide units in the polymers with dipodal moieties does not lead to a higher mean chain-to-chain separation. Moreover, the highest overall chain-to-chain distance has been observed in the polymer P6 family. This fact may be explained by two opposing effects of the increasing number of oxyethylene sequences of the podal arms. On the one hand, the increased number of oxyethylenes results in higher lateral volume, which should increase the interchain distances. On the other hand, increasing the number of oxyethylene sequences brings about an increase in the number of ether groups and also in the overall conformational mobility of the side arms. The higher conformational mobility of the ether groups, together with the increase in the number of these groups, implies an increase in the density of ether-amide group interactions, which is likely to decrease the number of amide-amide hydrogen bonds and hence diminish the interchain interactions in the same way that the addition of water to the polyamides results in an increase in the density of the polymer-water system, even though the density of the dry polyamide is greater than $1 \mathrm{~g} / \mathrm{cm}^{3}$. Interactions of the oxygen of the water molecules or of the ether groups

Journal of Polymer Science: Part A: Polymer Chemistry DOI 10.1002/pola break some of the interamide bonds, leading to better chain packaging and a decrease in the overall polymer volume. ${ }^{30}$

Comparing the series of dipodal and crown moieties, we have observed the amorphous halo of the polymers with dipodal subunits at higher angles than the angle corresponding to the polyamides with crown ether residues (Fig. 7); this implies that the interchain distances are higher for the polymers bearing crown moieties. The higher conformational mobility of the two podal arms compared with the cycle structure of the crown ethers contributes to the decrease in the interchain distances.

\section{SEM}

Studies of membranes of polymer C6PPD with SEM (Fig. 9) suggest a fairly compact surface morphology, in agreement with the low porosity discussed in the next section. There were indications of phase separation (jellyfish-like structures), although it should be stressed that this did not occur throughout the whole analyzed surface. The phase separation could be attributed to the evaporation of a polymer solution containing a low percentage of semisoluble, highly swollen, threaded polyamide cycles. However, the fact that this kind of morphology is also seen in the electron micrographs of membranes of 15-crown- 5 ether methacrylic could mean that it is a characteristic of crown polymers. This will be discussed in more detail in a future publication.

\section{Transport Studies}

The polyamide derivatives presented in this work are characterized by a limited number of polar groups in their chains. The study of acid

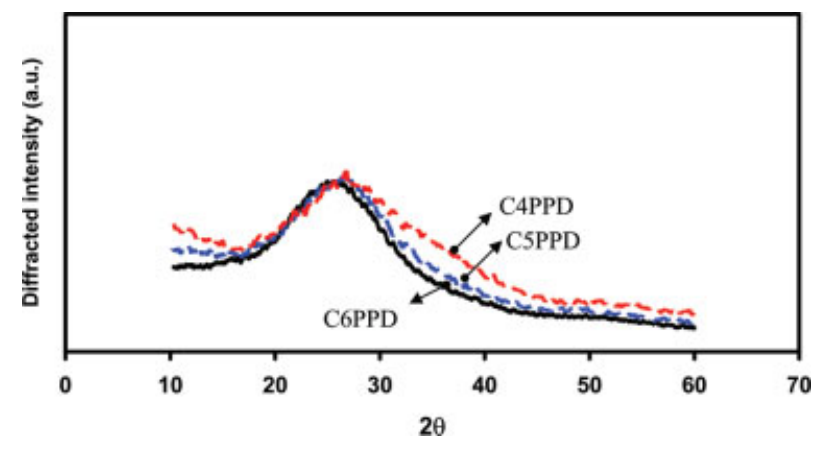

Figure 8. X-ray diffraction patterns of C4PPD, C5PPD, and C6PPD (which are represented by red, blue, and black lines, respectively). 

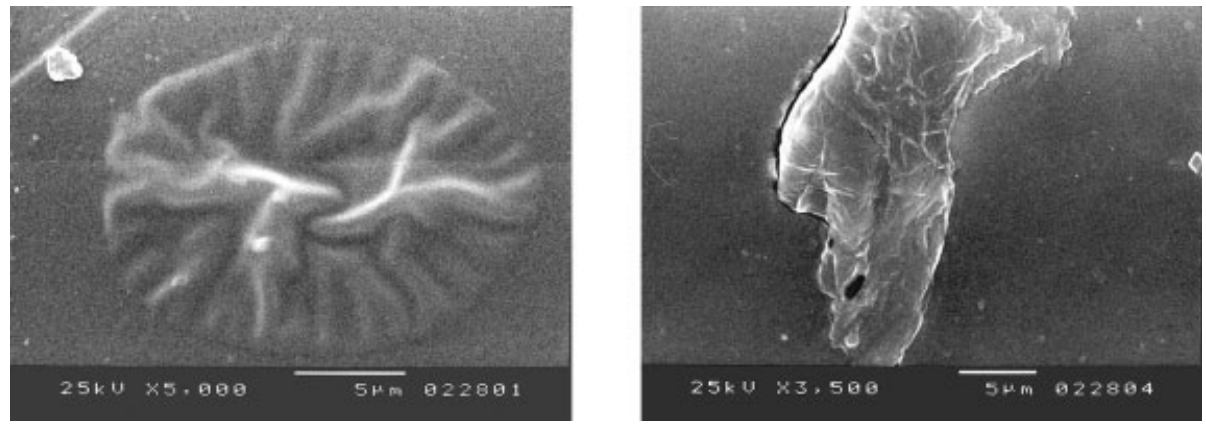

Figure 9. Comparison of the C6PPD surface morphology (left) and that found on the surface of a 15-crown-5 ether methacrylic polymer film [poly $(1,4,7,10,13$-pentaoxacyclopentadecan-2-ylmethyl methacrylate); right].

transport through membranes of these polymers, through the diffusion coefficients, will provide information on the effect of the number of polar groups on the transport mechanism. In addition, these measurements provide details via the permeability coefficients on the degree of compaction of the polymeric structure in membranes. Generally, with steady-state transport processes through membranes, there is a time lag associated with the dissolution of the permeant species to a constant level before a steady state is achieved. In addition, an increase in the induction period will be found with an increase in the interaction between the permeant species and the polymeric structure. ${ }^{31}$

The effect of the crown and size on the transport of $\mathrm{HCl}(250 \mathrm{mM})$ was studied. The calculated transport property values are presented in Table 3. The increase in the crown size results in an increase in both the permeability and diffusion coefficients. This shows that a possible interpretation of the effects on the diffusion and permeability coefficients may be made on the basis of the free volume concept. ${ }^{32}$ With increasing crown ether size, the distance between the polymeric chains will increase, and consequently, the permeation will tend to increase, whereas at the same time the ability to bind and to find hydrogen ions will decrease: This can be measured by a decrease in the time lag. This results from the increase in both the crown size and the free space between polymeric chains, that is, the increase in the overall free volume. In addition, the results suggest that the increase in the crown size will increase the plasticizing effect on the polymer structure, in close agreement with DSC results.

The transport of $\mathrm{HCl}$ through dipodal-containing polyamides shows that the presence of an increasing number of ether groups leads both to an extension in the time lag and to changes in the final steady-state permeation. This increase of both the steady-state permeation and time lag may imply strong interactions between the permeant molecule and polymer. ${ }^{33}$ As previously pointed out, the increase in the number of oxyethylene groups will increase the conformational mobility of these groups, facilitating the interaction of these groups with amide moieties and thus increasing the polymeric compaction, as indicated by the X-ray diffraction results. However, the permeation results show

Table 3. Permeability Coefficient $(P)$, Apparent Diffusion Coefficient $\left(D_{\text {ap }}\right)$, and Time Lag $(\theta)$ for $0.25 \mathrm{M} \mathrm{HCl}$ Diffusion through Different Polyamide Membranes (See Table 1)

\begin{tabular}{lccc}
\hline Polymer & $P\left(10^{-14} \mathrm{~m}^{2} \mathrm{~s}^{-1}\right)$ & $\theta(\mathrm{s})$ & $D_{\text {ap }}\left(\mathrm{m}^{2} \mathrm{~s}^{-1}\right)$ \\
\hline C4PPD & $3.64( \pm 0.18)$ & $11,525( \pm 190)$ & $5.78( \pm 0.42) \times 10^{-15}$ \\
C5PPD & $6.33( \pm 0.16)$ & $3,173( \pm 173)$ & $8.40( \pm 0.55) \times 10^{-14}$ \\
C6PPD & $19.57( \pm 0.40)$ & $1,071( \pm 59)$ & $3.15( \pm 0.20) \times 10^{-13}$ \\
P4PPD & $0.44( \pm 0.01)$ & $7,365( \pm 548)$ & $3.62( \pm 0.30) \times 10^{-14}$ \\
P6PPD & $1.10( \pm 0.03)$ & $23,631( \pm 446)$ & $1.13( \pm 0.04) \times 10^{-14}$ \\
P8PPD & $20.38( \pm 0.52)$ & $33,137( \pm 398)$ & $8.05( \pm 0.30) \times 10^{-15}$ \\
\hline
\end{tabular}


Table 4. Mechanical Properties and Moisture Absorption of the Polyamides

\begin{tabular}{|c|c|c|c|c|c|}
\hline \multirow[b]{2}{*}{ Polymer } & \multicolumn{2}{|c|}{ Mechanical Properties } & \multicolumn{3}{|c|}{ Moisture Absorption } \\
\hline & $\begin{array}{c}\text { Tensile } \\
\text { Strength } \\
(\mathrm{MPa})\end{array}$ & $\begin{array}{l}\text { Young's } \\
\text { Modulus } \\
(\mathrm{GPa})\end{array}$ & $\begin{array}{l}\text { Water } \\
\text { Uptake } \\
(\%)\end{array}$ & $\begin{array}{c}\text { Mol of } \\
\mathrm{H}_{2} \mathrm{O} / \text { Repeating } \\
\text { Unit }\end{array}$ & $\begin{array}{c}\text { Mol of } \\
\mathrm{H}_{2} \mathrm{O} / \text { Equiv } \\
\text { of Amide }\end{array}$ \\
\hline C6MPD & 65 & 2.9 & 10.0 & 3.3 & 1.1 \\
\hline C6PPD & 63 & 2.4 & 10.7 & 3.5 & 1.2 \\
\hline C6DDS & 53 & 2.2 & 9.2 & 3.7 & 1.2 \\
\hline C6DDE & 75 & 2.6 & 7.7 & 2.9 & 1.0 \\
\hline $\mathrm{C} 6 / 6 \mathrm{~F}$ & 57 & 2.3 & 7.3 & 3.3 & 1.1 \\
\hline P8MPD & 55 & 1.7 & 6.5 & 2.6 & 0.9 \\
\hline P8PPD & 48 & 1.9 & 6.5 & 2.6 & 0.9 \\
\hline P8DDS & 54 & 1.7 & 5.8 & 2.7 & 0.9 \\
\hline P8DDE & 58 & 1.7 & 5.6 & 2.5 & 0.8 \\
\hline $\mathrm{P} 8 / 6 \mathrm{~F}$ & 59 & 2.6 & 5.3 & 2.7 & 0.9 \\
\hline
\end{tabular}

that $\mathrm{HCl}$ plays an important role in these interactions. With an increase in the podand structure, the number of ether groups available for interaction with $\mathrm{HCl}$ also increases, and this leads to an increase in the time necessary to reach the steady state; this is supported by dielectric measurements upon polyamide membranes, just below $T_{\mathrm{g}}$. Under these conditions, a current is observed, probably due to the hydrogen bonds between amide groups, which can lead to proton hopping by oscillations from a nitrogen atom of an amide group to an oxygen atom of a neighboring one. This may justify the increase in the permeability coefficient with an increasing in the number of oxyethylene groups in the presence of $\mathrm{HCl}^{34-36}$

\section{Solubility}

The solubilities of the polymers derived from $\mathrm{C} 6$ and P8 are presented in Table 2. All the polymers derived from $\mathrm{C} 4, \mathrm{C} 5, \mathrm{C} 6, \mathrm{P} 4, \mathrm{P} 6$, and $\mathrm{P} 8$ monomers are soluble in aprotic, polar solvents, and most of them are in protic cresol. ${ }^{4,5}$

The pendant alicyclic or acyclic oligo(ethylene oxide) structure controls the solubility of all the polyamides, and the influence of the diamine residue on this property is small. Thus, the solubility differences between them can be considered to be negligible.

The enhanced solubility compared with that of fully aromatic polyamides allows the ready processability of these polymers for transformation through casting into films, membranes, or coatings or through solution spinning into spun fibers and so forth. DOI 10.1002/pola

\section{Mechanical Properties}

All the polyamides showed good film-forming ability, and this makes them suitable for testing as fixed-site carrier membranes for cation separation, ion-selective membranes, selective solidliquid extraction of cations, and other technological applications.

The tensile strength and Young's modulus of the polyamides derived from the $\mathrm{C} 6$ and $\mathrm{P} 8$ diacid monomers (Table 4) ranged from 48 to $75 \mathrm{MPa}$ and from 1.7 to $2.9 \mathrm{GPa}$, respectively. The mechanical properties of the polyamides derived from the $\mathrm{C} 4$, C5, P6, and P8 diacid monomers are similar to those of the polymers derived from $\mathrm{C} 6$ and $\mathrm{P} 8$ and vary between 48 and $103 \mathrm{MPa}$ (Young modulus) and 1.7 and $3.3 \mathrm{GPa}$ (tensile strength). ${ }^{4,5}$ The mechanical properties of these polyamides can be considered to be acceptable for nonoriented films made through casting on a laboratory scale without a postthermal treatment. The results are also comparable to values reported earlier for other aromatic polyamides. ${ }^{37-39}$

\section{Water Absorption}

Aromatic polyamides are polymers with polar amide groups that absorb water mainly through the interactions with these groups. The water uptake of polyamides greatly influences the polyamide properties and conditions the final application of these high-performance materials, particularly because the absorbed water diminishes $T_{\mathrm{g}}$ and influences the mechanical, electrical, and dielectric properties.

The polyamides described here have three amide groups per structural unit, in addition to 
different sequences of oxyethylene units. Both amide and ether moieties are polar groups that will influence the water uptake through hydrogen-bonding interactions with water. Thus, the percentage of water uptake of our polyamides is determined by two opposing factors: (1) the number of polar groups per structural unit increases the uptake, and (2) the presence of larger oxyethylene sequences increases the number of ether groups and also the conformational mobility of these groups, facilitating their interaction with the amide moieties and thus reducing the percentage of available polar amide groups to interact with water, diminishing the overall water uptake. ${ }^{39,40}$

The isothermal sorption of water at $65 \%$ relative humidity was measured, and the values were related to the polyamide structure. Table 4 shows the data obtained as the water absorption percentage for polyamides derived from the diacids C6 and P8. The table shows the molecules of water per structural unit and molecules of water per amide group. The moisture absorption of polyamides is between 5.3 and $10.7 \%$, and the water uptake per structural unit is between 2.5 and 3.7

Although there is an increase in the number of ether groups from C4-derived polyamides to C5- and C6-derived polyamides, in terms of molecules of water per structural unit, the water uptake is similar in the series. This means that the extra hypothetical water uptake of the additional ether groups is counteracted by the interaction of these ether groups with the amide linkages. This is also observed in the podal family. In terms of the water uptake percentage, the increase in the molecular weight of the structural unit with the increment in oxyethylene sequences in the pendant structure leads to a lower percentage of absorption.

The financial support provided by the Ministerio de Educación y Ciencia-Feder (MAT2005-01355), Conselho de Reitores das Universidades Portuguesas (Acção Inegrada Luso-Espanhol E-4/05), and Junta de Castilla y León (BU003A05) is gratefully acknowledged.

\section{REFERENCES AND NOTES}

1. Pedersen, C. J. J Am Chem Soc 1967, 89, 70177036.

2. Pedersen, C. J. J Am Chem Soc 1967, 89, 24952496.

3. Vögtle, F.; Weber, E. Angew Chem Int Ed Engl $1979,18,753$
4. Calderón, V.; García, F. C.; de la Peña, J. L.; Maya, E. M.; García, J. M. J Polym Sci Part A: Polym Chem 2006, 44, 2270-2281.

5. Calderón, V.; García, F.; de la Peña, J. L.; Maya, E. V.; Lozano, A. E.; de la Campa, J. I.; de Abajo, J.; García, J. M. J Polym Sci Part A: Polym Chem, 2006, 44, 4063-4075.

6. García, J. M.; de la Campa, J. G.; Schwarz, G.; de Abajo, J. Macromol Chem Phys 2001, 202, 12981305.

7. Valente, A. J. M.; Polishchuk, A. Y.; Lobo, V. M. M.; Burrows, H. D. Langmuir 2000, 16, 6475-6479.

8. Yamazaki, N.; Higashi, F.; Kawataba, J. J Polym Sci Polym Chem Ed 1974, 12, 2149.

9. García, F.; García, J. M.; Rubio, F.; Tiemblo, P.; Guzmán, J.; Riande, E. Polymer 2004, 45, 1467-1475.

10. Rey, J; García, F.; García, J. M. In Síntesis y Polimerización Radical de Monómeros Metacrílicos con Subestructuras Benzoéter Corona y Benzopodandos en la Cadena Lateral; Universidad de Burgos, 2004.

11. Maya, E. M.; Lozano, A. E.; de la Campa, J. G.; de Abajo, J. Macromol Rapid Commun 2004, 25, 592-597.

12. Delavid, Y.; Gibson, H. W. Macromolecules 1992, 25, 4859-4862.

13. Gibson, H. W.; Ge, Z.; Huang, F.; Jones, J. W.; Lefebvre, H.; Vergne, M. J.; Hercules, D. M. Macromolecules 2005, 38, 2626-2637.

14. Gong, C.; Gibson, H. W. J Am Chem Soc 1997, 119, 5862-5866.

15. Kricheldorf, H. R.; Rabenstein, M.; Maskos, M.; Schmidt, M. Macromolecules 2001, 34, 731-722.

16. Kricheldorf, H. R.; Böhme, S.; Schwarz, G. Macromolecules 2001, 34, 8879-8885.

17. Kricheldorf, H. R.; Schwarz, G. Macromol Rapid Commun 2003, 24, 359-381.

18. Kricheldorf, H. R.; Böhme, S.; Schwarz, G.; Schultz, C.-L. Macromol Chem Phys 2003, 204, 1539-1546.

19. Kricheldorf, H. R.; Vakhtangishvilli, L.; Schwarz, G.; Schulz, G.; Kruger, R.-P. Polymer 2003, 44, 4471-4480.

20. Kricheldorf, H. R. Macromolecules 2003, 36, 2302-2308.

21. Kricheldorf, H. R.; Böhme, S.; Schwarz, G.; Schultz, C.-L. Macromol Chem Phys 2003, 204, 1636-1642.

22. Gibson, H. W.; Nagvekar, D. S.; Yamaguchi, N.; Bhattacharjee, S.; Wang, H.; Vergne, M. J.; Hercules, D. M. Macromolecules 2004, 37, 7514-7529.

23. Molecular Mechanics MMFF: Spartan '04 for Windows; Wavefunction: Irvine, CA, 2004.

24. Fan, S.-C.; Schwarz, G.; Kricheldorf, H. R. J Macromol Sci Pure 2004, 41, 779-790.

25. Kricheldorf, H. R.; Schwarz, F.; Fan, S.-C. High Perform Polym 2004, 16, 543-555.

26. Ayala, V.; Maya, E. M.; García, J. M.; de la Campa, J. G.; Lozano, A. E.; de Abajo, J. J Polym Sci Part A: Polym Chem 2005, 43, 112-121.

Journal of Polymer Science: Part A: Polymer Chemistry 
27. Alvarez, J. C.; de la Campa, J. G.; Lozano, A. E.; de Abajo, J. Macromol Chem Phys 2001, 2002, 3142-3148.

28. García, J. M.; Álvarez, J. C.; de la Campa, J. G.; de Abajo, J. J Appl Polym Sci 1998, 67, 975981.

29. Rabiej, S. Fibres Text East Eur 2005, 13, 30-34.

30. Starkweather, H. W. J Appl Polym Sci (II) 1959, 5, 129 .

31. Hamilton, C. J.; Murphy, S. M.; Tighe, B. J. Polymer 2000, 41, 3651-3658.

32. Valente, A. J. M.; Polishchuk, A. Y.; Lobo, V. M. M.; Geuskens, G. Eur Polym J 2002, 38, 13-18.

33. Valente, A. J. M.; Burrows, H. D.; Polishchuk, A. Y.; Domingues, C. P.; Borges, O. M. F.; Eusébio, M. E. S.; Maria, T. M. R.; Lobo, V. M. M.; Monkman, A. P. Polymer 2005, 46, 5918-5928.
34. MCrum, N. G.; Read, B.; Williams, G. Anelastic and Dielectric Effects in Polymeric Solids; Dover: New York, 1991.

35. Baker, W. O.; Yager, W. A. J Am Chem Soc 1942, 64, 2171

36. McCall, D. W.; Anderson, E. W. J Chem Phys 1960, 32, 237.

37. Fernández, A. M.; Lozano, A. E.; de Abajo, J.; de la Campa, J. G. Polymer 2001, 42, 7933.

38. Ferrero, E.; Espeso, J. F.; de la Campa, J. G.; de Abajo, J.; Lozano, A. E. J Polym Sci Part A: Polym Chem 2002, 40, 3711.

39. Ferreiro, J. J.; de la Campa, J. G.; Lozano, A. E.; de Abajo, J. J Polym Sci Part A: Polym Chem 2005, 43, 5300-5311.

40. Ayala, V.; Maya, E. M.; García, J. M.; de la Campa, J. G.; Lozano, A. E.; de Abajo, J. J Polym Sci Part A: Polym Chem 2005, 43, 112-121. 